\title{
Are there martial art styles that represent natural systems?
}

\author{
Joachim T. HAUG*, \& Carolin HAUG \\ Department of Biology II and GeoBio-Center. Ludwig-Maximilians-Universität Munich (Germany)
}

Recepción: 28/10/2015; Aceptación: 14/12/2015; Publicación: 28/12/2015.

\begin{abstract}
For didactics, systematically structured teaching contents are desirable, and natural systems would be most comprehensible. We tested whether serrada-escrima styles (SES), a type of Filipino martial arts, represent a natural system. Natural systems are considered to have an inner coherence. This means that based on some elements of the system the other elements can be predicted, based on knowledge of the characteristics of the elements of the system. SES is a good candidate to test this hypothesis, as it embraces only a relatively small set of techniques. It appears that SES indeed represents a natural, coherent system with 12 elements that can be grouped into three also coherent sets, each with four techniques. One basic pre-assumption is necessary to make SES a natural system; this pre-assumption is derived from knowledge of medieval European sword fighting, more precisely Messerfechten. We furthermore discuss indications for the historic background of SES.
\end{abstract}

Keywords: Messerfechten; serrada-escrima styles; medieval sword fighting; Daumenhaltung; Filipino martial arts; Medieval martial arts.

\section{¿Hay estilos de artes marciales que representen sistemas naturales? \\ Resumen}

A efectos didácticos, son deseables los contenidos de enseñanza estructurados sistemáticamente, y los sistemas naturales serían los más comprensibles. Hemos puesto a prueba si la serrada escrima (SES), un tipo de arte marcial filipina, representan un sistema natural. Se considera que los sistemas naturales tienen una coherencia interna. Esto significa que partiendo de algunos elementos del sistema pueden llegar a predecirse otros, basándose en el conocimiento de las características de los elementos del sistema. La SES es una buena candidata para probar esta hipótesis, ya que solo abarca un conjunto relativamente pequeño de técnicas. Parece que la SES, de hecho, representa un sistema natural y coherente con doce elementos que pueden ser agrupados en tres conjuntos también coherentes, cada uno compuesto de cuatro técnicas. Para hacer de la SES un sistema natural es necesario asumir un supuesto a priori; este pre-supuesto se deriva del conocimiento del combate con espada medieval europeo, concretamente del Messerfechten. Este trabajo discute además algunos aspectos históricos de la SES.

Palabras clave: Messerfechten; estilos de serrada-escrima; combate con espada medieval; Daumenhaltung; Artes marciales filipinas; Artes marciales medievales.

\section{Há estilos de artes marciais que representam sistemas naturais?}

\section{Resumo}

Aos efeitos didácticos, são desejáveis os conteúdos de ensino estruturados sistematicamente. Tendo isso como base, os sistemas naturais seriam mais compreensivos. Colocámos à prova a serrada escrima (SES), um tipo de arte marcial filipina, representando um sistema natural. Considera-se que os sistemas naturais têm uma coerência interna. Isto significa que, partindo de alguns elementos do sistema, se pode chegar a se prever outros, baseandose no conhecimento das características dos elementos do sistema. A SES é uma boa candidata para se comprovar esta hipótese, na medida que ela abrange um conjunto relativamente pequeno de técnicas. Parece que a SES, de facto, representa um sistema natural e coerente com doze elementos que podem ser agrupados em três conjuntos também coerentes, cada um composto de quatro técnicas. Para se fazer da SES um sistema natural, é necessário assumir um pressuposto prévio. Este pressuposto prévio deriva do conhecimento do combate com espada medieval europeu, particularmente o Messerfechten. Este trabalho discute também alguns aspectos históricos da SES.

Palavras-chave: Messerfechten; estilos de serrada escrima; combate com espada medieval; Daumenhaltung; Artes marciais filipinas; Artes marciais medievais.

\section{Introduction}

Martial arts is a field that science in a strict sense appears to have hardly touched. Scientific studies dealing with 'martial arts' focus on 'fighting sports', e.g. social effects (e.g. Goodger \&

\footnotetext{
* E-mail: joachim.haug@palaeo-evo-devo.info. Address: Department of Biology II and GeoBio-Center, LMU Munich, Großhaderner Str. 2, 82152 Planegg-Martinsried (Germany).
} 
Goodger, 1977; Jamesa \& Jonesa, 1982; Lantz, 2002), physiological effects of training and competition (e.g. Filaire, et al., 2001; Brudnak, Dundero, \& Van Hecke, 2002), specific injuries (e.g. Zetaruka, et al., 2000; Pieter, 2003; Destombe, et al., 2006) or biomechanics of single techniques (e.g. Cavanagh \& Landa, 1975; Sforza, et al., 2000, 2002; Pucsok, Nelson, \& Ng, 2001; Estevan, et al., 2014). A growing field of research are historical aspects of martial arts (e.g. Tan, 2004; Ahna, Hongb, \& Parkc, 2009; Kurochkin \& Khorasani, 2015).

The "science" of martial arts as a whole "system", not restricted to the sportive aspects, appears to be left to the practitioners (e.g. Davis, 1999; Kernspecht, 2000; Sprague, 2003). We agree with the notion of Khan (1999) that martial arts in principle is nothing more than a "geometry competition" (p. 56). In consequence, each movement in martial arts can be described based on its geometry, i.e. orientation in space. We therefore propose that there should be a systematic scientific investigation of martial arts based on their geometry.

A "system" in a scientific sense should allow a sorting of techniques according to characteristics of the techniques. This principally differs from the sorting systems that most martial arts offer to their practitioners, as these usually focus on few specific characteristics of a technique rather than all aspects that indeed characterise the technique. A strict system (as here anticipated) describing martial arts should facilitate many aspects of martial arts. It should positively affect:

(1) teaching (and learning) as it will allow to group related techniques together (sorting system);

(2) adjusting to certain needs of the practitioner (as exact characters of the techniques are given);

(3) solving difficulties in sportive set of rules as it will exactly allow to prohibit techniques that possess a certain character or set of characters;

(4) communication and comparison between the martial arts;

(5) historical comparisons.

The question is if there are already martial art styles that represent systems in a scientific sense that can act as a basis for developing a general system for martial arts. Such scientific systems should only contain elements that have a specific relation to other elements of the system (see also discussion in Haug \& Haug, 2015). In other words: If one knows some techniques of the system, other techniques can be predicted based on the known ones. Predictability is an important aspect of the scientific method and a system with elements as described must be considered to be coherent. Like for historical sciences it will be difficult to apply aspects of falsifiability as a criterion in a scientific treatment of martial arts (Cleland, 2001, 2002). Coherence in the described sense remains the main criterion for such a treatment.

\section{Methodology}

\subsection{Criteria}

The aim of the study is testing whether there are examples of martial art styles that indeed represent an entire system, or whether martial art styles always represent a mere conglomerate of techniques that are preferred by the practitioner (sometimes also called system, as long as the techniques are fixed, usually by an authority, cf. e.g. Leung, 1998; Wiley, 1999). A system will be identified as being natural and complete based on one criterion: inner coherence. This resembles principles in systematic biology where inner coherence and the minimisation of assumptions (Ockham's Razor, parsimony) is the only test for the correctness of a supposed system (e.g. Hennig, 1994; Assis, 2009).

Martial art styles with only few techniques are the best candidates for an initial test of such an approach. For example, the Kung Fu styles referring to Yip Man only teach six forms (three weaponless, one wooden dummy, one double knife and one long pole; Leung, 1998); often these forms consist of eight sections, more or less equalling a technique in other styles. Thus these styles have significantly less techniques than, for example, Shotokan Karate-Do with 26 or 27 forms and in some cases 65 movements per form (Nakayama, 1991). Serrada-escrima styles, a specific type of Filipino martial arts, as generally taught, include defences against 12 attacks, 3 defences for each 
attack (see Wiley, 1999), making a maximum of just 36 techniques, in its core competence single stick against single stick. However, some of these defences are used against several attacks, reducing the entire number of techniques even further. The extremely low number of techniques within serrada-escrima styles (in the following referred to as SES) make them a perfect candidate for an initial test of coherence.

\subsection{Approach}

Based on the techniques of SES an idealised system is presented. This idealisation is constructed to be "complete", i.e. coherent. All techniques are presented as stereo-anaglyphs of computer-generated 3D models. This representation is chosen to avoid any variance caused by real-life practitioners. The idealised system is compared to the actual set of techniques. The system is considered to be natural if it is complete, i.e. if sets of techniques forming a consistent group (subsystem) are all included in the original set of techniques. If a technique is missing, the style must be considered "incomplete", lacking coherence, therefore not representing a system in the strict sense.

The actual workflow of this approach was the following: (1) the techniques of the style were studied; (2) based on these, other techniques were "predicted"; and (3) then it is checked whether this predicted technique is indeed present in the original teaching curriculum. This whole process is not unidirectional, but reciprocal. This process of reciprocal illumination is a scientific principle, which is not a vicious circle, but a hermeneutic spiral resulting in a knowledge gain in each cycle (e.g., Reif, 2002). The difficulty of this process is its presentation, as presentation in the normal sense must remain unidirectional. Therefore, in the following the ideal sytem is presented first. Then differences to the actual practiced style are pointed out.

\subsection{Basic assumption}

The very direct defensive positions of SES are in most cases characterised by a forward movement, the defending weapon arm is almost straight. This means in many cases that the incoming force of the strike is not deflected, but must be stopped (blocked) by countering the incoming energy with own energy of the same amount. This can be perfectly applied with a stick, which will absorb most the incoming force (the rest will be absorbed by the bodies of the two practitioners). While nowadays filipino martial arts are trained with the stick, originally they were performed with a blade weapon; this should also be true for the roots of SES. Executed with a blade weapon, straight forward blocking would most likely heavily damage the edge of the blade. This would make the edge of the blade useless and could even endanger the practitioners to get hit by tiny shrapnels into the eye or other vulnerable areas. Yet, among practitioners the historical use of blade weapons for the techniques of the SES is often emphasised (cf. Wiley, 1999). Apparently, all students of the famous Grandmaster Angel Cabales were taught SES with a stick, not with a blade weapon (Wiley, 1999 and authors therein); there is no direct evidence how the blade was used in SES. We offer a possible interpretation for this issue which will form a pre-assumption for the remaining test of coherence.

Medieval martial arts (correctly "Late medieval and early renaissance martial arts"), in the following referred to as European sword fighting, ESF, is one of the best available historical source of the application of blade weapons. Especially German Messerfechten (e.g. Talhoffer, 1467, after Hergsell, 1887) comprises techniques similar to most filipino martial art styles. In Messerfechten there are two different ways how to hold the handle of the weapon. The first, normal hold has the (front) edge of the blade facing forward. The alternative way of gripping of the weapon is with the edge of the blade facing sidewards, the thumb is placed on the flat, normally inner side of the blade (e.g. Talhoffer, 1467, after Hergsell, 1887, his Tafel 231). Because of the specific position of the thumb, this hold is also called thumb hold (Daumenhaltung). This special hold allows very straight and forward oriented defensive movements, as the attacking blade hits with its edge not onto the edge of the own weapon, but onto the flat (usually outer) side. For this reason (and others, see below) we will test the assumption that SES with a bladed weapon in thumb hold "makes sense", 
i.e., would represent a coherent system. As the attacker is thought not to perform SES he will hold his blade in normal grip.

The specific way of holding a blade weapon in thumb hold leads to difficulties when trying to use it in a counter strike; normal strikes are not possible as then the flat side of the blade would hit the target instead of the edge. Therefore, one criterion for judging the possibility if the thumb hold could explain the specifics of the SES is whether its special strikes can be executed with the thumb hold. Due to the assumed closeness of SES and ESF, reference is given to strikes and positions in ESF to enable a detailed future comparison.

As a short historical note: The Spanish arrived on the Philippines in the $16^{\text {th }}$ century, a time when medieval fencing was still practiced in some areas of Europe (Mair, 1542; von Meyer, 1570; Sutor, 1612, after Scheible, 1949). The Spanish sword fighting might have influenced filipino fencing, introducing the thumb hold to filipino martial arts. The thumb hold could also have been independently discovered, at least it appears to be known on the Philippines (see, e.g., Siebert, 1995, his fig. 163 lower right).

\section{4. "Material"}

The basis for this study are the techniques taught in SES which are termed: Inside sweep (inside block), outside sweep, fanning, roof block, cross block, shield block (also shoulder block), outside pass (outside block), umbrella block, two step pass, one step pass, and punch block. This set of techniques, at least its terminology, differs slightly from the set of techniques for SES presented by Wiley (1999), but reflects how SES was introduced at first to the authors of this publication.

\section{Description of movement sequences}

\subsection{Finishing sequences}

All SES sequences end with a specific (sub-)sequence. This is a kind of finishing sequence. While it could be argued that this most likely historically formed ending might not be of interest for the here presented approach, it is included for two reasons: 1) completeness and 2) it includes several specific strikes which probably hold the information how the weapon was held be the practitioner in times when this sequence was designed. There are two variants of this ending. They are presented before the actual techniques, the defensive techniques, so these can then simply be stated to be followed by one of the two finishing sequences.

\subsubsection{Finishing sequence 1}

The first finishing sequence is usually referred to as inside (this refers to a right-right handed or left-left handed pair of practitioners only, description here and in the following for rightright), the right foot is in front. The single steps are (Fig. 1):

(1) Fast horizontal rotation of the arm inwards, the front edge hits the side of the head (Zwerchhau). Left hand guards the arm of the opponent.

(2) Fast horizontal rotation of the arm outwards, the back edge hits the side of the head (Zwerchhau).

(3) Fast vertical rotation of the arm inwards, the front edge hits the weapon arm from below (Knichelhau.) The guard of the left hand is withdrawn, in order to prevent hitting the own hand.

(4) Step in between, the weapon is shortly withdrawn before the next hit, left hand guards the arm of the opponent.

(5) Fast twist of the wrist and vertical rotation, the front edge hits the arm from above. The guard of the left hand is withdrawn, in order to prevent hitting the own hand.

(6) Step in between, the weapon is shortly withdrawn before the next hit, left hand guards the arm of the opponent.

(7) Fast horizontal rotation of the arm outwards, the back edge hits the side of the body, left hand guard is withdrawn for security. 
(8) Steps 6) and 7) are repeated two times.

The high horizontal rotation strikes could in principle be executed with a normal hold instead of a thumb hold. In this case the flat sides of the weapon would be used to hit (cf. Prellhau, Sutor, 1612, after Scheible, 1949). All other strikes would not make sense with the flat side. Bringing the edge in a correct position with a normal hold would demand for a rapid change of bending and flexing the wrist. The bending and flexure would make these cuts/hits ineffective.

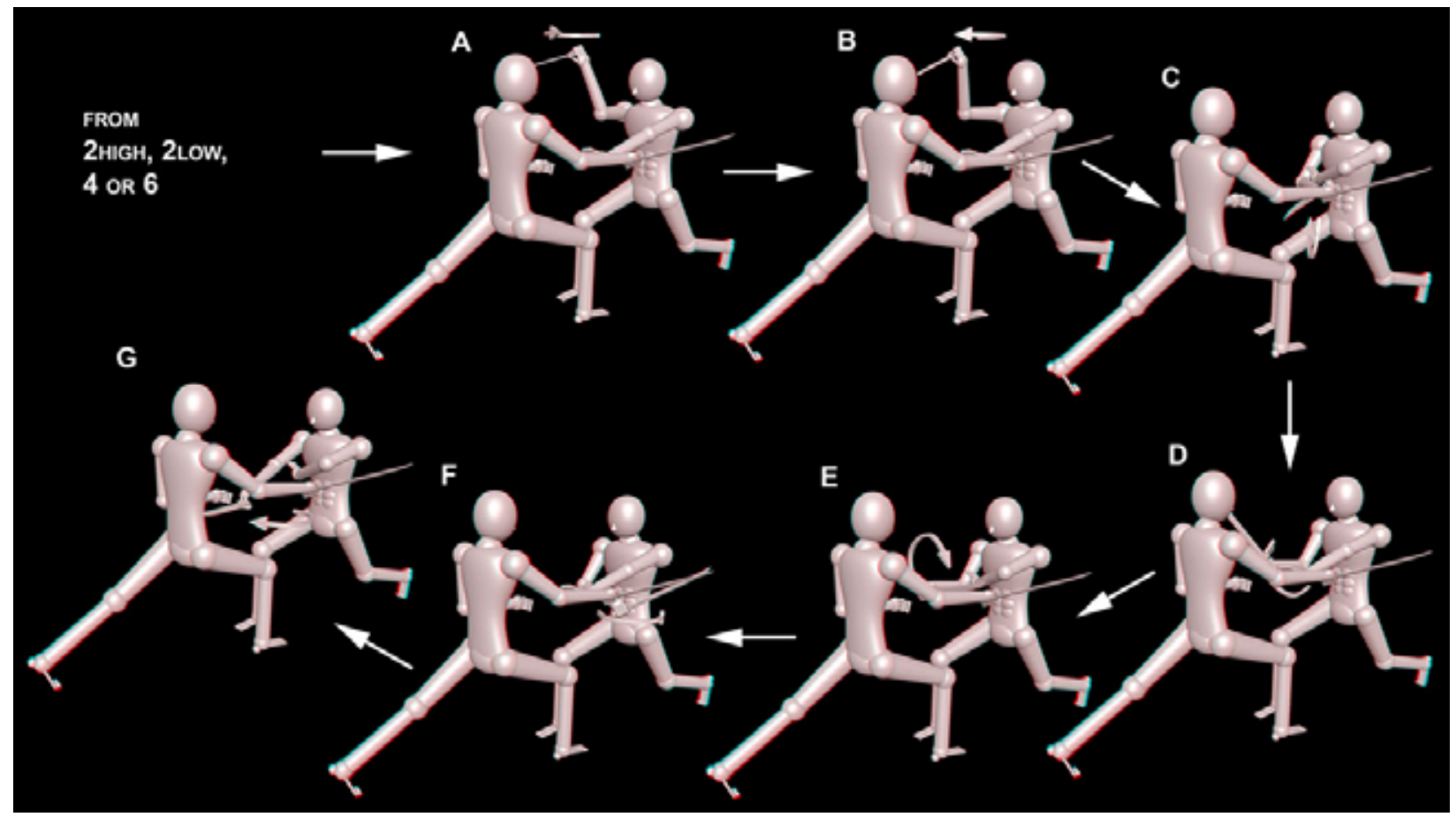

Figure 1. Finishing sequence 1. A. Zwerchhau. B. Zwerchhau. C. Knichelhau. D. Guard with left hand. E. Knichelhau. F. Guard with left hand. G. Strike.

\subsubsection{Finishing sequence 2}

The second finishing sequence is referred to as outside (this refers again to a right-right handed or left-left handed pair of practitioners only), the left foot is in front. The single steps are (Fig. 2):

(1) Fast horizontal rotation of the arm outwards, the back edge hits the side of the head (Zwerchhau). Left hand guards the arm of the opponent.

(2) Fast horizontal rotation of the arm inwards, the front edge hits the side of the head, (Zwerchhau).

(3) Fast vertical rotation of the arm outwards, the back edge hits the arm of the opponent, left hand guard is withdrawn for security.

(4) The flat side of the blade is used to guard the opponents arm.

(5) Left hand guards the opponent's arm, the weapon is withdrawn in preparation of the next strike.

(6) Horizontal rotation of the arm outwards the back edge hits the side of the body, left hand guard is withdrawn for security. The movements 5) and 6) are repeated two times

\subsection{Defensive movement sequences}

In total 12 defensive movement sequences result from the SES movements, which can be grouped into sets of four such techniques each. Two sets are described first; they are similar in the fact that the own weapon is used for defensive purposes first, while in the third set the left hand is used first. 


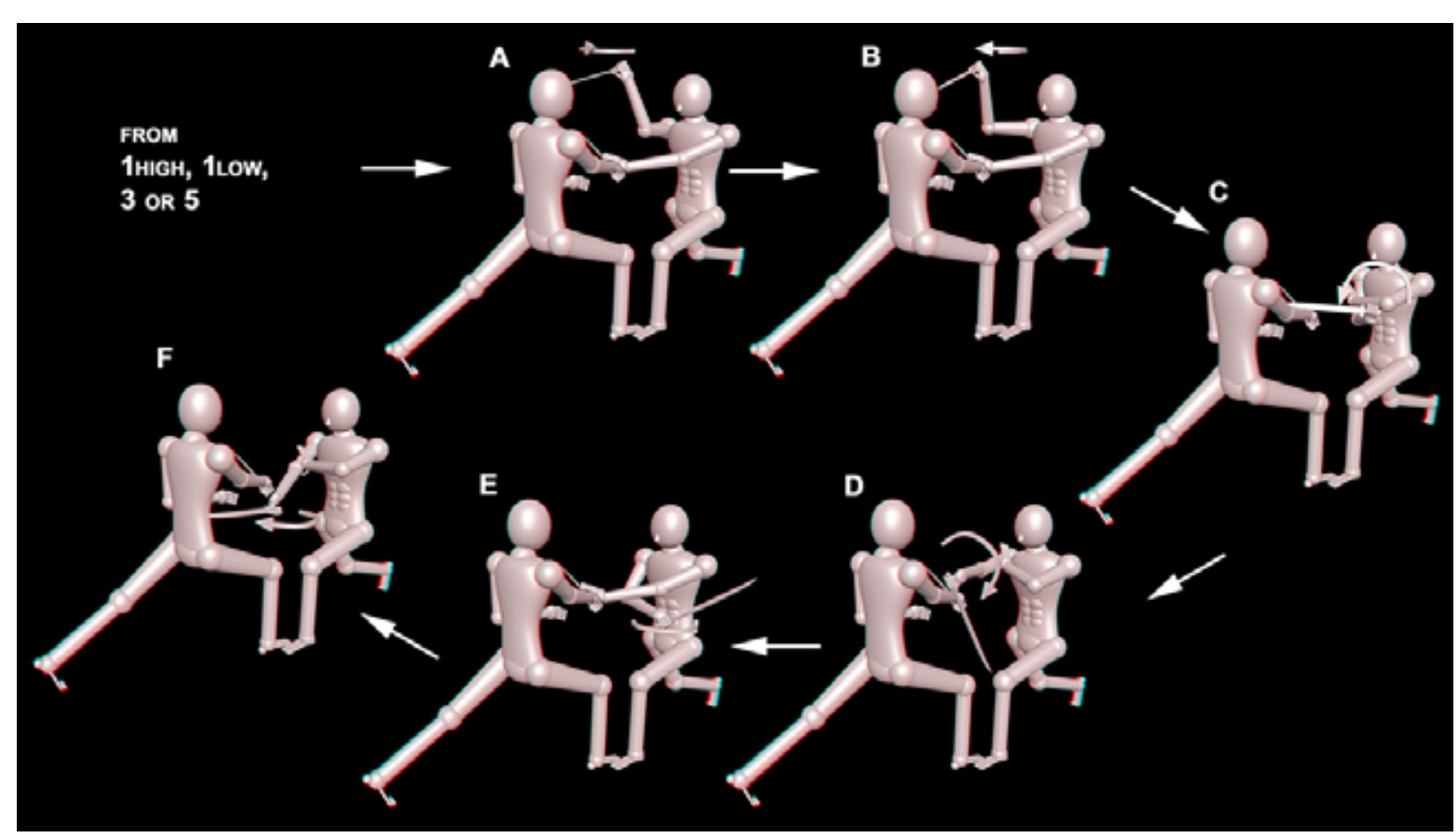

Figure 2. Finishing sequence 2. A. Zwerchhau. B. Zwerchhau. C. Knichelhau. D. Guard with weapon. E. Guard with left hand. F. Strike.

The eight techniques of the first two sets can be grouped into two sub-sets of four in several ways. The first one presented is only one possibility of several ones which will be discussed afterwards. The eight techniques are numbered as 1 high, 1 low, 2low, 2high, 3, 4, 5 and 6 . This numbering refers to a "historical" numbering; it is especially thought to provide a basis for future comparisons of different martial art styles. All uneven numbers defend the left body side, all even ones the right body side (referring to right hand, reversed in left hand). The numbering mainly reflects a kind of statistics how often these specific techniques are found in different martial are styles. All martial art styles appear to have a movement equivalent to 1, most to 2, and so on; only very few styles have 5 and even less 6 (pers. obs.). A differentiation between high and low (in 1 and 2) is often difficult. A future more rigid naming system should substitute this only preliminary naming, yet for the moment it is the best available one.

This is also one reason why the first sorting is presented in the chosen way here. The first set contains only 1-4 and thus should have the highest chances also for practitioners of different martial arts to recognise these techniques.

The defensive movement sequences are identified as four different techniques in reference to the four major attacking angles which are used in many filipino martial arts and others (yet not always with the same numbering). As the characteristics of the defensive movement sequences will show, this appears to be a natural arrangement (following reciprocal illumination and coherence as criteria). The four angles can be summarised as attack against left upper body (traditionally angle 1), right upper body (angle 2), left lower body (angle 3) and right lower body (angle 4). All other angles in different martial art styles appear to represent derivatives of these angles.

\subsubsection{Half sword defensive movement sequences}

The first four defensive movement sequences are united by the fact that they can be executed in the so-called half-sword position (Halbschwert, Talhoffer, 1467, after Hergsell, 1887). This means the left hand is placed close to the tip of the blade, gripping the flat side of the blade, or pressing firmly from behind the blade to secure the defensive position. Although these positions might appear somehow "primitive", it is in fact a very effective hold (e.g., Talhoffer, 1467, after Hergsell, 1887). The tip of the blade always points left. This means these techniques can be used as 
emergency techniques after a sudden drawing of the blade from the scabbard, which is usually carried on the left hip (for a right-handed person; e.g., Hoff, 2008).

One consequence of this hold is the correctness of the four angles as natural entities. First, the differentiation between high and low angles becomes obvious. Holding the sword up in halfsword position can provide a continuous protection for attacks against the upper body, holding it low provides a continuous protection against the lower body. Furthermore, footwork is necessary. Attacks against the left body side demand for a right foot in front position, otherwise it would not be possible to place both hands on the weapon while still protecting the body. Therefore, there are two parameter pairs: high-low and left foot-right foot. The combination of both results in four different regions which directly correspond to the four traditional angles.

(a) Half sword defensive movement sequence angle 1 (block 4, roof block): Right foot is forward. The butt (= pommel) of the weapon is pushed in the direction of the face of the opponent. The tip of the blade points down, left and backwards (all 45 degrees). This position closes angle 1 optimally. Left arm, if not in half sword, is placed with the forearm behind the blade, left hand down, left elbow up. The depicted variation (Fig. 3A) is a moderately executed, not too aggressive execution of this technique. A more aggressive execution would include an almost completely straight arm. If the opponent would only pretend an attack (feinting), or the attack is not forceful enough, the opponent would get hit by the butt. The position resembles the position Wacht in ESF (von Meyer, 1570). Yet, the orientation of the edge resembles in fact a Zornhut, but in this case the other foot should be in front. The position could also be compared to Schrankhut, yet the high Schrankhut would have the point to the front. This problem also demonstrates that a correlation of positions with thumb hold to most positions in normal hold is often ambiguous. The position of the blade is a preparation for a horizontal rotation strike. Therefore, directly after this movement finishing sequence 1 is executed.

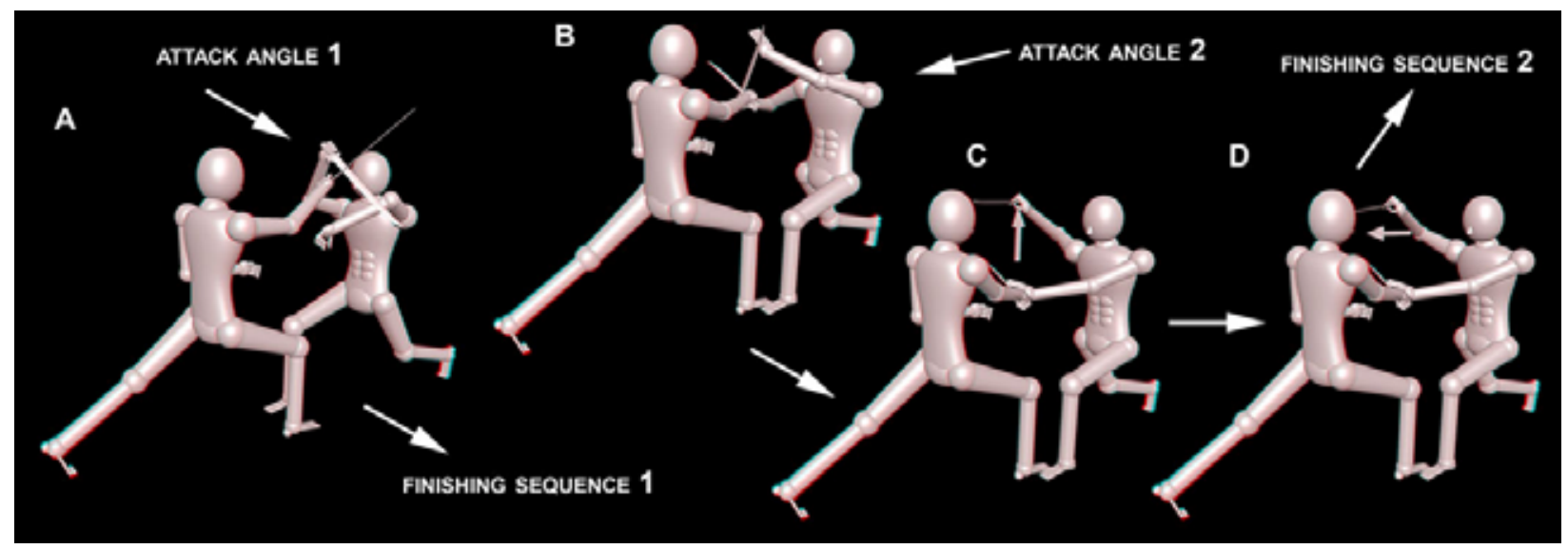

Figure 3. Defences 4 and 1high. A. Defence 4, roof block. B-D. Sequence of outside sweep. B. Defence 1high, outside sweep. C. Raising the blade. D. Forward thrust.

(b) Half sword defensive movement sequence angle 2 (block 1high, outside sweep): Left foot is forward. The tip of the own blade is pushed in the direction of the face of the opponent, the tip points therefore up, left and forwards. This position closes angle 2 optimally. Left arm, if not in half sword, is placed with the edge of the hand on the blade. The fingers point right and up. Again this represents a moderate execution of the technique (Fig. 3B-D). If the attack is only pretended (feinting) or not forceful enough the opponent will get hit. This position is somewhere between a Pflug in ESF (orientation of the edge) and Einhorn (general position). After contact, the left hand will guard the opponent's arm while the own blade loses contact to the opponent's weapon. The hand is raised while the tip is kept in position (this results in a slight twist of the weapon); from this position the weapon is thrusted forward. Afterwards finishing sequence 2 is executed.

(c) Half sword defensive movement sequence angle 3 (block 2low, inside sweep): Right foot is forward. The butt of the weapon is pushed in the direction of the belly of the opponent. The tip points up, left and back. This closes the angle 3 optimally. Left arm, if not in half sword, is placed with the forearm behind the blade, left hand up, left elbow down (Fig. 4A). In a more forceful execution the arms 
would be almost straight, the butt could hit the opponent's belly. The position has no easily identifiable correspondence in ESF. The position is a preparation for a horizontal rotation strike (Zwerchhau), and can be directly followed by finishing sequence 1 .

(d) Half sword defensive movement sequence angle 4 (block 3, fanning): Left foot is forward. The tip of the own blade is pushed in the direction of the belly of the opponent. Tip points down, left and forwards. This closes angle 4 optimally. Although this technique can be performed in half sword, it is also possible to use the left hand to directly guard the arm of the opponent (Fig. 4B-D). In a more aggressive execution the tip could hit the opponent. Based on the orientation of the edge of the blade the position is quite similar to the position Alber, yet it is higher, closer to the position Ochs. The left hand guards the hand of the opponent, the tip is swung to the front, followed by a forward thrust. Afterwards finishing sequence 2 is executed.

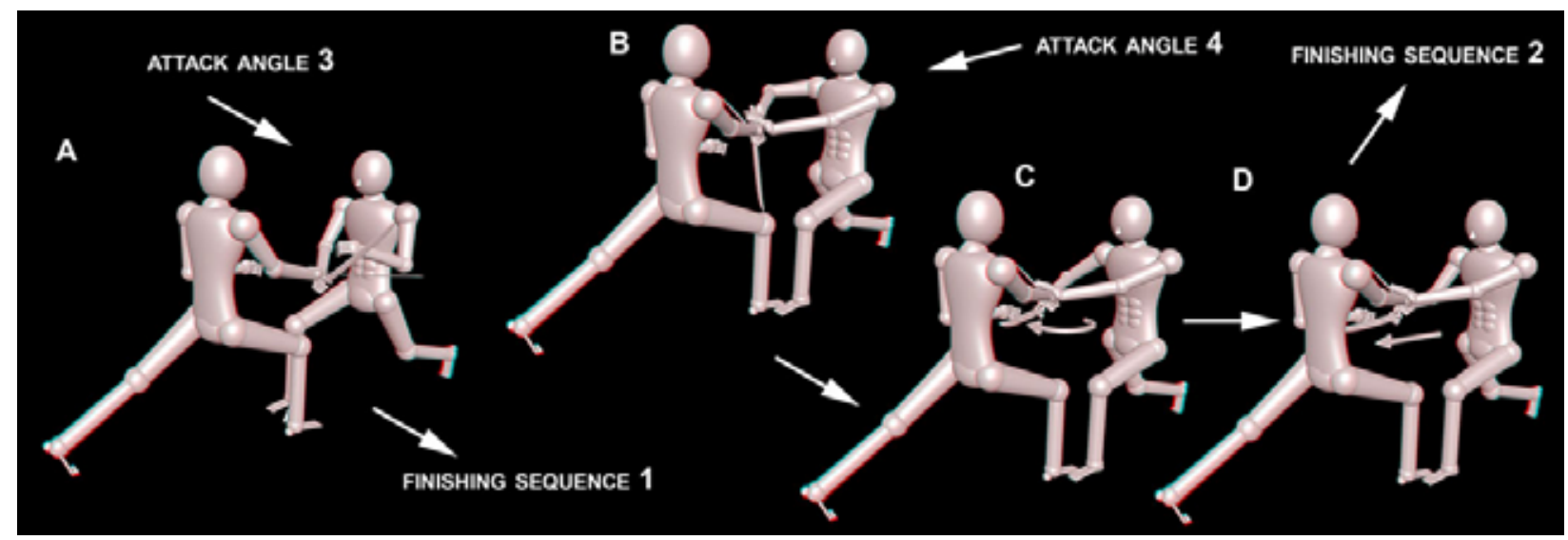

Figure 4. Defences 2 low and 3. A. Defence 2low, inside sweep. B-D. Sequence of fanning. B. Defence 3, fanning. C. Relocating the blade. D. Forward thrust.

\subsubsection{Spear defensive movement sequences}

The other set of four techniques is ideal for two-handed weapons with a wide grip. As the tip always points right, the arms never become crossed (in a right-handed grip). Therefore, these techniques could be used, for example, with a spear and are referred to as spear-defensive movements (as opposed to half sword).

(a) Spear defensive movement sequence angle 1 (block 2 high, inside sweep): Right foot is forward. The tip of the weapon is pushed in the direction of the face of the opponent. Handle is slightly moved right, the tip therefore points up, right and forward. Left hand points forward and guards the hand of the opponent (Fig. 5A-D). Again this execution is moderate, a more aggressive execution would hit the opponent with the tip. The position almost perfectly corresponds to the position Einhorn in ESF, yet is a bit lower, closer to a Pflug. After the contact, the left hand continues guarding, the right hand is moved slightly back and up, the tip is slightly dropped. The blade can be thrusted forward. After the thrust the arm is suddenly rotated inward (Zwerchhau). Then finishing sequence 1 is executed.

(b) Spear defensive movement sequence angle 2 (block 5, shield block): Left foot is forward. The butt of the weapon is pushed forward towards the face of the opponent, while twisting the wrist (Winden in European sword fighting), the tip "stays" outside. In consequence, the tip points down, right and backward (Fig. 5E). This move may be difficult at first. It is important not to swing out the tip but to twist the forearm and getting the tip of the blade to the outside in this way. Left hand guards the arm of the opponent (Fig. 5F). As before, in a less moderate execution the butt could hit the opponent. The position could correspond to a Hangetort in ESF, yet this term refers in fact to a group of different positions. This position is a preparation for a rapid horizontal rotation of the weapon inward (Zwerchhau to the head). The left hand pushes the arm of the opponent slightly down. This action is then followed by finishing sequence 2 . 


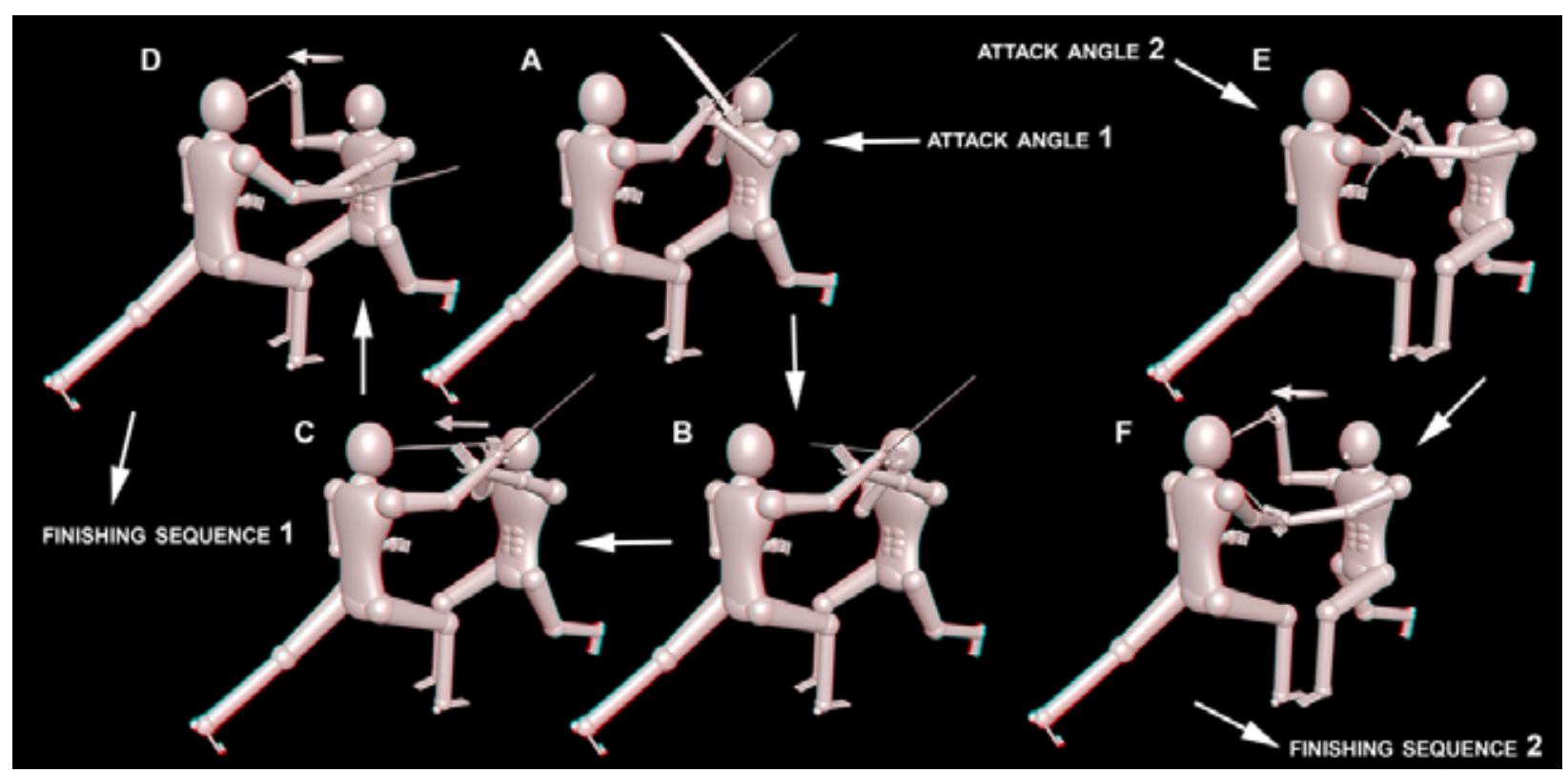

Figure 5. Defences 2high and 5. A-D. Sequence of inside sweep. A. Defence 2high, inside sweep. B. Relocating the blade. C. Forward thrust. D. Zwerchhau. E-F. Sequence of shield block. E. Defence 5, shield block. F. Zwerchhau.

(c) Spear defensive movement sequence angle 3 (block 6): Right foot is forward. The tip of the weapon is pushed in the direction of the belly of the opponent. The tip points down, right, forward. As in the movement sequence before, the hand is twisted to reach this position (Winden). In a more aggressive execution the tip could hit the opponent. The position is between an Alber and Ochs in ESF. Left hand guards the arm of the opponent, while the right hand is moved slightly up, also the tip is raised. From here the weapon is thrusted forward. Then arm is rapidly rotated inward (Zwerchhau). Then finishing sequence 1 is executed (Fig. 6A-D).

(d) Spear defensive movement sequence angle 4 (block 1low, outside sweep/punch block): Left foot is forward. The butt of the weapon is pushed in the direction of the belly of the opponent. The tip points up, right and backward. In a more aggressive execution the butt could hit the opponent. The position has no real correspondence in ESF. The position is a preparation for a sudden horizontal rotation strike (Zwerchhau) inwards. Then finishing sequence 2 is executed (Fig. 6E, F).

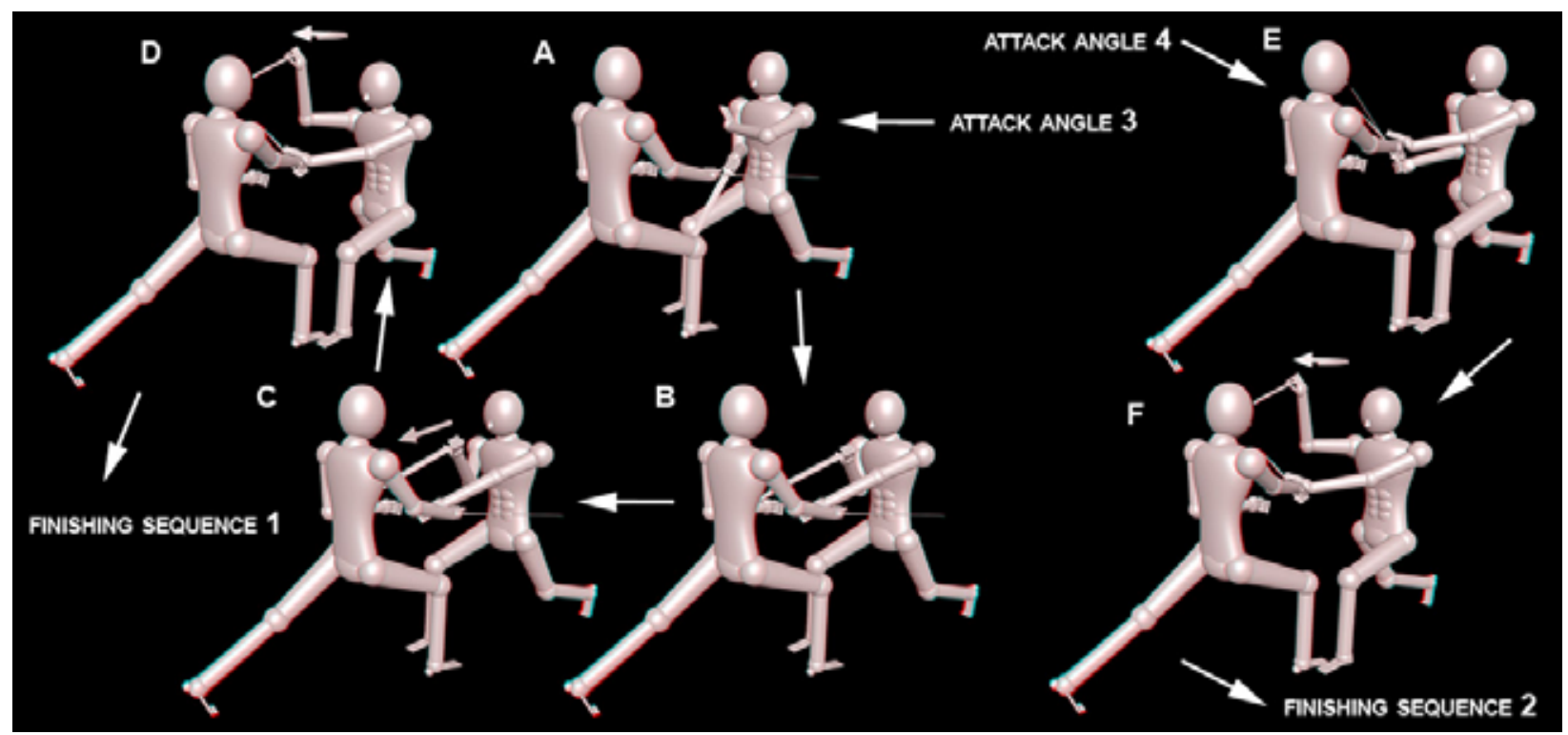

Figure 6. Defences 6 and 1low. A-D. Sequence of defence 6. A. Defence 6. B. Relocation of the blade. C. Forward thrust. D. Zwerchhau. E-F. Sequence of outside sweep. E. Defence 1low, outside sweep/punch block. F. Zwerchhau. 
The eight described movements could be described as static techniques as the incoming force must be fully withstood and absorbed. Alternatively, SES teach the transition from one position into another. In this way the incoming force can be partly redirected and does not need to be fully absorbed. For such combinations the chosen ordering into the two subsets works well. To redirect incoming force one has to change from one quadrant into the next on the same height (while "changing the feet"). The pairs are 1high-4 (and reverse, this accounts also for all following pairs), 2low-3, 2high-5, 1low-6. Additionally, 1high and 1low as well as 2 high and 2low are very similar and it is possible to push the blade of the opponent slightly up or down to change from the one to the other. This results in fact in two chains of movements: 4-1high-1low-6 and 5-2high2low-3. These two differ significantly in the possible close-quarter follow-up techniques (beyond the scope of this study). For future comparisons names for these chains are introduced: The first is termed circle1, the second circle2. The reversals of these chains are referred to as cross 1 and cross 2 .

\subsubsection{Left hand sweeping defensive movement sequences}

Besides the static eight defences with the weapon (and the resulting combinations) SES teaches four defences with the left hand. This can be described as derivations of the combined movements with the blade. Yet, they differ in the fact that they completely lack the blocking part; they are mere sweeping moves "catching" the opponent's arm from behind, redirecting or deflecting it slightly upward (high angles) or pressing it down (low angles). Different from the block-redirection combinations with the blade it is better not to make two steps, but performing directly the "second" step in order to partly avoid the incoming blow from the upper angles. For the lower angle at first no step forward is made, instead the hips are slightly moved back and the upper body is slightly bent forward.

(a) Left hand sweeping against angle 1 (5-2 sweep, outside sweep): The left hand moves from the left and pushes the incoming arm to the right and slightly up, while one makes a step left forward "out" of the direction of the attack. The sweep is followed by finishing sequence 2 .

(b) Left hand sweeping against angle 2 (4-1 sweep, umbrella): The left forearm moves up, left hand pointing right, elbow slightly higher than the hand. After making contact with the opponent's arm, the own arm is straightened. This pushes the arm of the opponent up and to the left. This is accompanied by a step right forward partly avoiding the incoming force. The left hand keeps contact with the arm of the opponent to guard it. The sweep is followed by finishing sequence 1 .

(c) Left hand sweeping against angle 3 (1low-6 sweep, one-step-pass, two-step-pass): The left hand starts on the left side, then pushes the incoming strike to the right and down with the own palm. While passing the attack the hip is slightly moved back. After passing by the attack the left foot makes one step forward. The sweep is followed by finishing sequence 2 .

(d) Left hand sweeping against angle 4 (2low-3 sweep, punch block): The left forearm moves down, fingers point to the right, pressing the incoming attack down and to the left. While passing the attack, the hip is slightly moved back. After passing by the attack the right foot makes one step forward. The left hand keeps contact to the arm of the opponent. Afterwards finishing sequence 1 is executed.

\section{Discussion and Evaluation}

\subsection{Why is this idealised system a natural coherent system?}

The eight defensive positions with the blade result from a strict combination of the three parameter pairs (up-down, left-right, backward-forward) that describe the orientation of the blade in a three-dimensional space. This already indicates that these eight positions represent a system, which is in itself coherent. From a functional point of view the 3D-diagonal orientation of the blade optimally closes its specific angle being oriented perpendicular to a possible incoming strike (cf. Kernspecht, 2000 for 3D diagonal). 
Furthermore, the eight defensive positions can be grouped into two subsets of four positions. These subsets are coherent, because if three of these techniques are given the fourth can be reconstructed based on it. Additionally, based on the first subset the second one can also be reconstructed. Thus, there are predictable techniques based on the parameters of the given techniques; three techniques should be sufficient to reconstruct all eight techniques. In this sense "coherence" of the system is scientific.

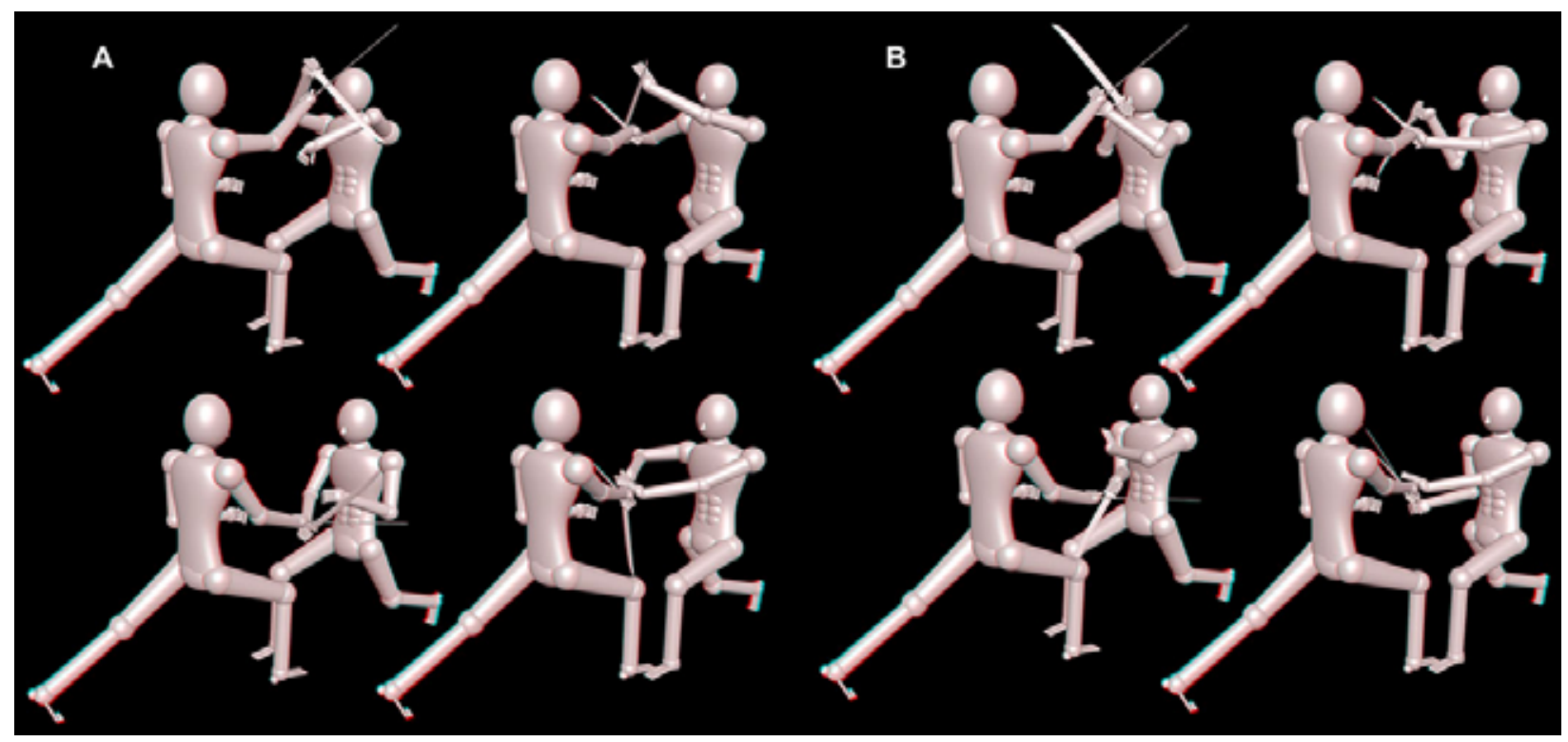

Fig. 7. Sorting 1. A. All defences with tip pointing left. B. All defences with tip pointing right.

The first presented grouping, tip left or half sword defences (Fig. 7A) and tip right or speardefences (Fig. 7B), is just one way of sorting, but well founded. As already mentioned, the tip-left quartet derives, e.g. from a drawing from the scabbard, while the other set derives from a position of the weapon on the right shoulder (cf. Luitger?, ca. 1300; Siebert, 1995). Also these two sub-sets appear to be coherent.

Another coherent sorting is tip up (Fig. 8A) and tip down (Fig. 8B). The condition "tip of the weapon up" for all four angles is also referred to as "candle stick" defences in Filipino martial arts. Both sets could be used with a very heavy, forward balanced weapon, to avoid sudden flipping up and down of such a forward balanced weapon.

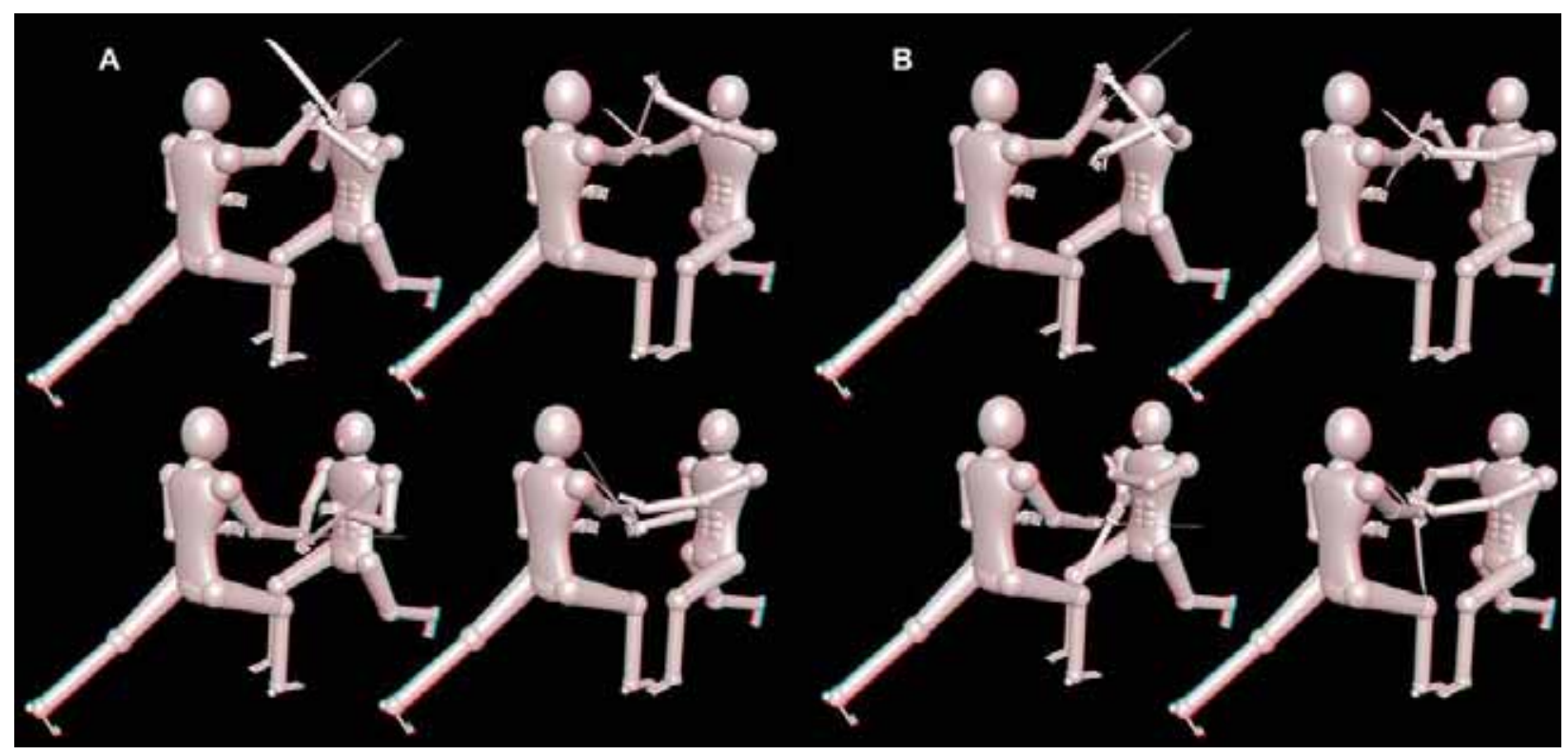

Figure 8. Sorting 2. A. All defences with tip pointing up. B. All defences with tip pointing down. 
A third coherent sorting is tip forward (Fig. 9A) or tip backward (Fig. 9B). The four defences with the tip forward would be of advantage if one wants to have a far distance from the opponent, or has a weapon optimised for stabbing. The complementary set with the tip pointing backwards are of advantage if one wants to be closer to the opponent (for example in order to continue with a close quarter or grappling follow-up technique) or has a weapon optimised for slashing and striking.

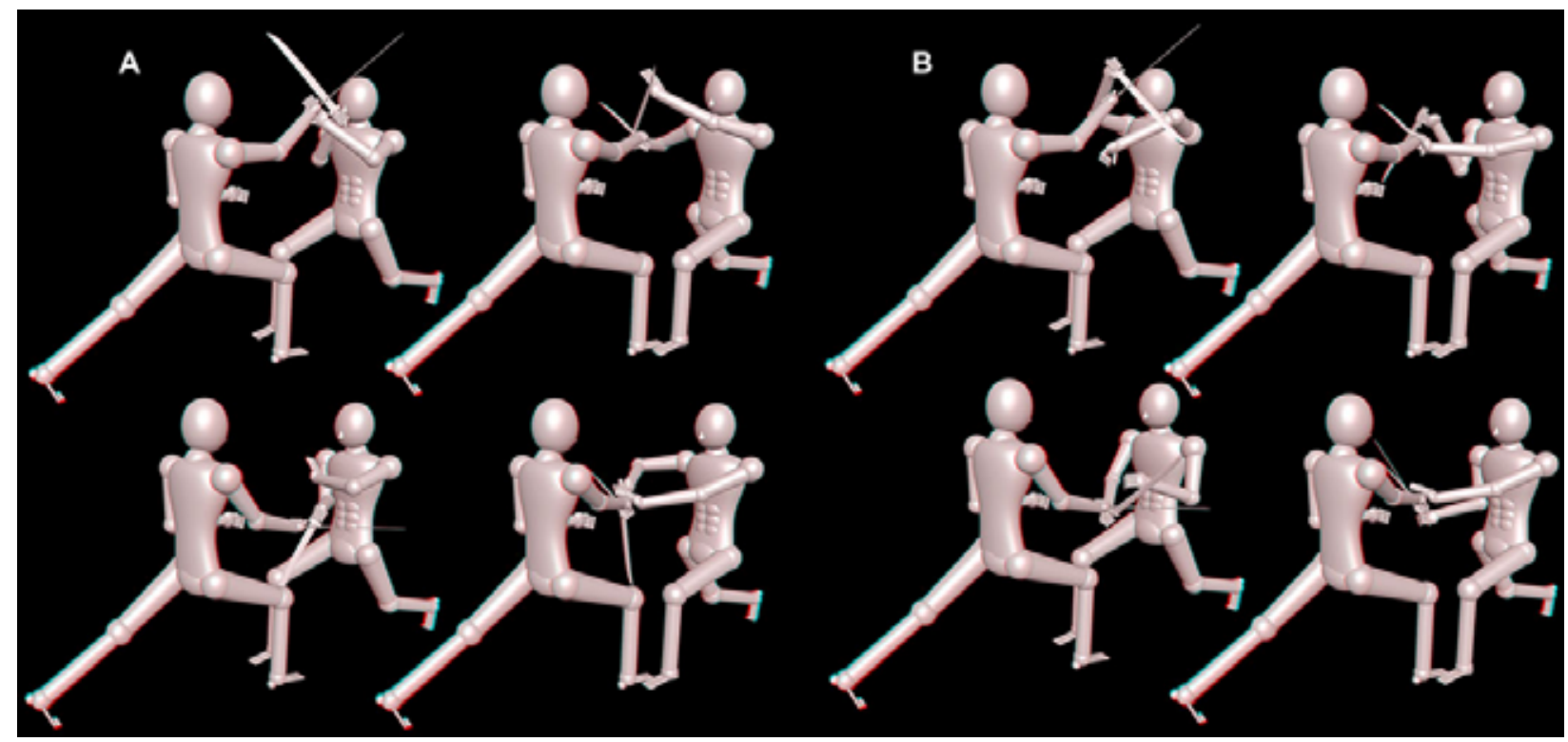

Figure 9. Sorting 3. A. All defences with tip pointing forward. B. All defences with tip pointing backward.

A fourth coherent sorting is according to their circles, i.e. all techniques of circle1 (Fig. 10A) vs. all techniques of circle2 (Fig. 10B). The advantage of this sorting is that from all angles the incoming attacks can be redirected into the same follow-up technique.

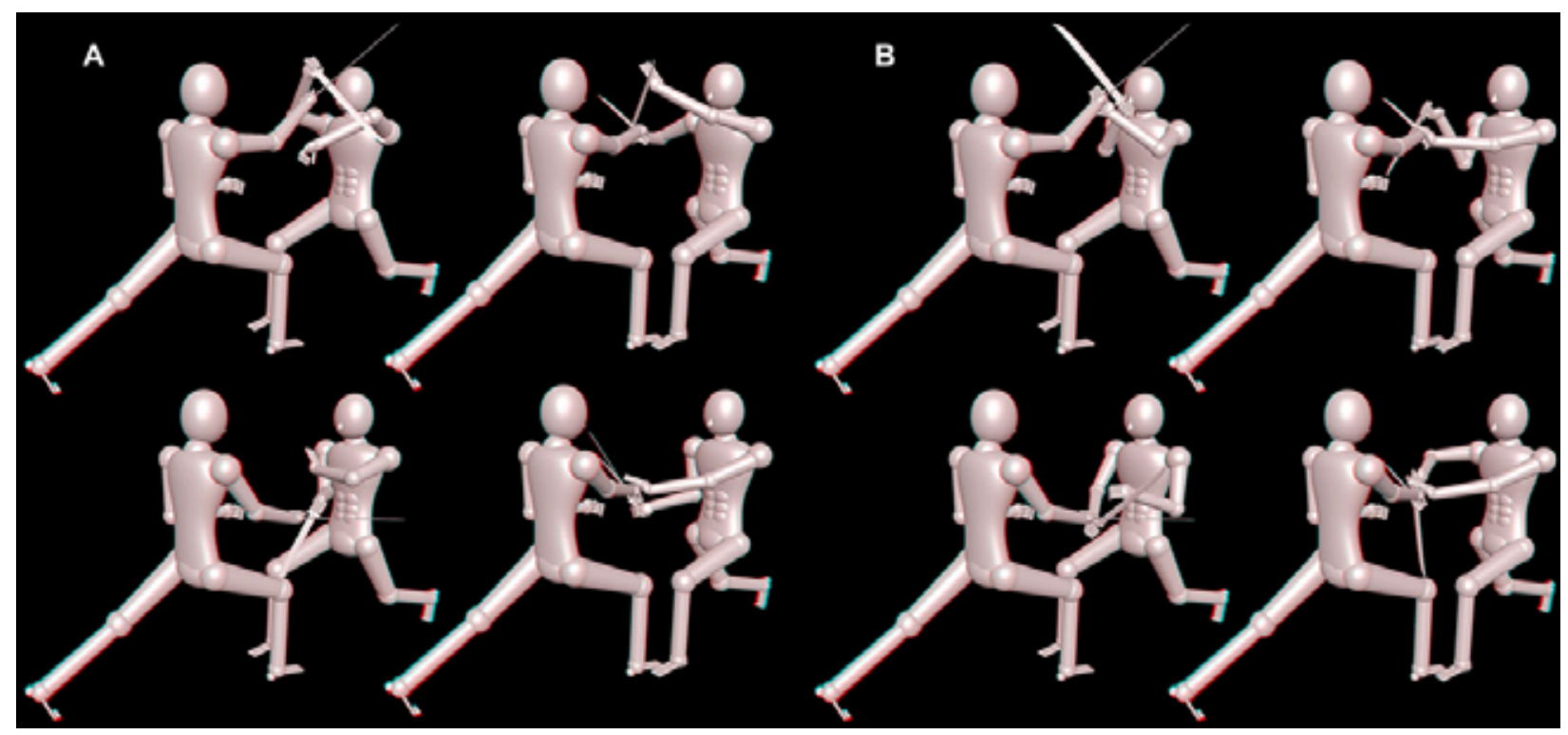

Fig. 10. Sorting 4. A. All defences forming circle1. B. All defences forming circle2.

Further sorting can differentiate between a static defence versus a re-direction. First, one could always deflect the attack vs. always use a static defence. One could also deflect all attacks from the left and block the ones from the right statically, if ones wants to end on the outside of the opponent (the complementary set accounts for the inside). It could also make sense to deflect high attacks but stop low ones if the opponent has a very long weapon that could hit the legs while 
passing. Vice versa, if there is a low ceiling it could be necessary to stop high attacks and pass low ones.

All these sorting possibilities appear to represent coherent sub-sets, indicating that the set of eight defensive techniques of the blade (16 if counting the deflections) represent also a coherent set and with this represent a natural system with many internal symmetries.

For the left hand there should be also 16 techniques. Yet, as discussed above, direct blocking should not be performed with the empty hand against a bladed weapon, thus eight techniques remain. Of these, only the subset with the four defences with the hand forward (tip forward) is included in SES, which increases the range and partly equalises the range advantage of the incoming armed attack.

The here presented techniques can well be performed with various weapons and are, for example, fully applicable for ESF. This will also potentially form a basis for future further-ranging comparisons. Compared to the stick, the orientation of a bladed weapon is more restrictive. This accounts for both blocking and striking. Yet, also for improving the precision of the movements with the stick these techniques are interesting to understand, e.g. for optimising the strike following the block.

\subsection{Deviations from a natural system}

SES appear to come close to the here presented idealised system, yet there are a few deviations from it that need to be discussed. First, it needs to be considered that the interpretations are entirely based on the assumption that the bladed weapon is held in thumb hold. If this assumption proves to be wrong, the whole discussion will prove wrong.

Based on the lock-and-block movement this assumption is likely to be correct: this series of cuts can only be performed as such with the blade in thumb hold. In standard hold the wrist would have to be iteratively strongly bent and flexed to orient the edge of the blade towards the aim (cf. Wiley, 1999, his figs. 13-5, 13-27, 13-105 13-129, 13-137, 13-175). This is neither an effective cut, nor a fast sequence. The assumption concerning the thumb hold is therefore seen as plausible and well-founded.

The thumb hold makes the body twists, which are taught in some SES between the moves, unnecessary. Body twists would make the movements relatively slow and cumbersome. Therefore, they are unlikely to represent authentic movements that were originally applied in filipino death matches. These body twists are most likely adapted from a boxing style, maybe due to the attempt to develop an unarmed version of SES.

Strikes with the thumb hold get most of the speed from the sudden twist of the forearm joint (not the wrist!) and are very fast, faster than a strike mediated from the shoulder or elbow joint. This further strengthens the assumption that the thumb hold represents an authentic part of the system of SES, which is known for its extremely fast and economic movements. From this point the assumption that SES could represent a natural system is not falsified. Yet, the following points could be seen as deviations from the ideal system:

(1) Position 6 is missing as a static position. It is included as the right hand part of the 'punch block', but only as the dynamic version 1 low-6. If we accept that this right hand move represents a position, the punch block should be separated between the left hand action (23 sweep) and the right hand action. The reverse 6-1low is not included and clearly missing.

(2) Position 6 is also avoided in the low defence with the tip down on the left body side of the defender. Instead SES propose a "low 4", the 'cross block' (high cross block cannot be differentiated from the roof block). A "low 4" is not part of the ideal system, it is very weak and cannot withstand pressure. The cross block can be used against a stab, but is also taught against strike 3 (Wiley, 1999). The fact that there are two version of the 4 position, roof block and cross block, emphasises that the cross block violates the consistency of the system.

(3) Both points show that position 6 is underrepresented. This could be attributed to the relatively short and strike oriented weapon usually used in SES. Position 6 is, as mentioned 
above, optimal for a thrusting optimised weapon. For the short and slashing oriented weapon usually used in SES position 6 is the least optimal one. Yet, the punch block could be a leftover of its original presence within the system.

(4) 'One step pass' and 'two step pass' both represent a 1low-6 sweep (with the left hand), yet differ in the footwork. Both should only be addressed to as one technique with two possible footworks (as in Wiley, 1999).

(5) 'Outside sweep' and 'inside sweep' do usually not differentiate between the high and the low version, the stick is often held straight up. The differentiation is more difficult to recognise than others and could be accepted as not directly deviating from the ideal system. It would be necessary to observe how practitioners execute these two techniques against high and low attacks and judge whether they indeed make an unconscious differentiation (cf. Wiley, 1999, his fig.13-2 where the blade is indeed forward).

(6) 'Umbrella block' does not directly correspond to a sweep. The incoming strike is at first blocked with the weapon and then swept with the left hand. Thus, also the footwork is at first "in", then "out". Yet, also this could be accepted as a minor deviation.

The deviations of SES from the ideal system can be seen as minor. Yet, different schools of SES appear to teach different details of SES, so some might be closer, others further away from it. We can consider the here presented idealised system as a variation of SES, which can act as a basis for future comparisons, especially also with ESF Messerfechten.

One consequence of the study is that it appears that SES is an example for an martial art style or system (sensu lato, i.e. a fixed set of techniques, not necessarily with an inner logic) that indeed is a coherent and complete system sensu stricto (i.e. a set of techniques with an inner coherence), at least, it comes quite close to it. Not all martial art styles are, thus, mere conglomerates of techniques. The question remains whether the Grandmaster of SES, Angel Cabales, intentionally designed the system as such by strict application of certain principles, i.e., if he was aware of this inner coherence. Alternatively, Cabales could have had an unconscious understanding for fighting comparable to the famous artist M.C. Escher's unconscious understanding of symmetry (Ernst, 1992). One indication that Cabales indeed fully understood the fact that his style is a true system with 12 elements is the reference to " 12 attacks and 3 defences each".

Other attacking angles in SES are direct derivatives from the first four angles. For an effective fighting style such as SES it seems illogical to differentiate between more angles than necessary and it appears that this was also taught by Cabales (Wiley, 1999). All defences against strike one also can be used against attack six, which is nothing more than a stab from angle 1.

It could therefore be speculated that the saying " 12 attacks and 3 defences each" originally refers not to the twelve strikes, which might have been introduced later for training purposes (cf. Wiley, 1999), i.e. being designed for educational reasons. Instead the "12, 3" reference could indicate the ideal system in the sense of 12 attacks meaning the 12 defences that are aggressively executed so that they are attacks (see Kernspecht, 2000) and three of these for each of the four original angles.

Other elements of SES are obviously not systematic. The empty hand section, the disarmings, as well as the arm locks are later add-ons (Wiley, 1999). Therefore, the statement has to be limited in the following way: the core part of SES represents a natural system.

\subsection{Comparison with other Filipino martial arts}

So why is SES different from other Filipino martial arts? Also other styles use the principle eight blocks (including the 6!) at least on a first glimpse. Yet, these styles are less strict than SES when it comes to the positioning of these movements. For example, often the "wrong" foot is in front when blocking (see examples in Siebert, 1995, e.g., his figs. 67, 73, \& 88). This is indeed possible with a stick; with a bladed weapon this would slightly change the position of the edge; with the wrong foot in front the blade could not have been held in thumb hold. If a blade is not held in thumb hold, there are significantly more positions (work in preparation), there are additional 
parameters necessary to characterise each technique, the subsets of techniques become less predictable or even unpredictable.

Therefore, other escrima styles may well be also true systems, yet with a significantly larger number of elements, which will make testing of coherence more complicated and must be postponed for future larger-scaled studies.

\subsection{Historical interpretation}

In fact, this must remain an attempt to a historical interpretation as no real historic data are available. Yet, there are certain indications within the system (sic!) of SES that indicate a certain original application. There are no defences at the side of the body, all are in front of the practitioner. There are also no evasion movements to the side or back, the whole foot work is only slightly diagonally to the front and back, but still very linear (sometimes practiced on a beam); this results in a very static position. Also the attacks executed after the defences are not expansive but restricted to the area in front of the practitioner.

This hints to two facts. SES is used to defend ground (based on the footwork) in limited space (based on defences and counter attacks), e.g. in a military formation. The simplicity and economy of SES could indeed indicate an original military use. The history of filipino martial arts has indicated an original use in war rather then in self defence (Siebert, 1995). SES clearly has characteristics - simple, economic, ground defending, applicable in formation and limited space (within streets, buildings, jungle) - that would make it very effective for military use.

This assumption could explain the historic origin of the highly constricted patterns of movement, e.g. the lack of sideways evasion. Yet, the true history of SES awaits historic research.

\section{Conclusions}

(1) There are martial arts that can be considered (or at least come close) to be coherent systems in a scientific sense, for example, serrada-escrima styles.

(2) SES is not only coherent as whole, but contains further coherent subsets.

(3) SES, as a small set of techniques, was comparably simple to test, styles with more techniques will correspond to significantly larger systems with more elements.

(4) Medieval sword fighting remains an important source for understanding blade weapons.

(5) The simplicity of SES might be coupled to an original use for military purposes.

The here presented approach is seen as promising for understanding martial arts from a scientific point of view. Yet, it remains a first step and demands for further larger-scaled approaches.

\section{Acknowledgements}

We are grateful to two anonymous reviewers (one of them trained with Angel Cabales himself) and the editor Carlos Gutiérrez-García for comments on the manuscript. Our sincere thanks go to our training partners for their efforts to teach us SES and to inspire our furthergoing studies which led to this paper, especially Marcus 0. Thudium, Bernd Borchardt, Holger Morell, and André Hahn. We would like to thank all people programming freely available software used for this study, such as Blender or OpenOffice.

\section{References}

Ahna, J.D., Hongb, S.H., \& Parkc, Y.K. (2009). The Historical and Cultural Identity of Taekwondo as a Traditional Korean Martial Art. The International Journal of the History of Sport, 26, 17161734. 
Assis, L.C.S. (2009). Coherence, correspondence, and the renaissance of morphology in phylogenetic systematics. Cladistics, 25, 528-544.

Brudnak, M.A., Dundero, D., \& Van Hecke, F.M. (2002). Are the 'hard' martial arts, such as the Korean martial art, TaeKwon-Do, of benefit to senior citizens? Medical Hypotheses, 59, 485491.

Cavanagh, P.R., \& Landa, J. (1975). A Biomechanical Analysis of the Karate Chop. Annual Meeting of the American College of Sports Medicine, New Orleans, Louisiana.

Cleland, C.E. (2001). Historical science, experimental science, and the scientific method. Geology, 29, 987-990.

Cleland, C.E. (2002). Methodological and epistemic differences between historical science and experimental science. Philosophy of Science, 69, 474-496.

Davis, A. (1999). The Art and Science of Serrada. In M.V. Wiley (Ed.), The secrets of Cabales Serrada Escrima (pp. 58-61). North Clarendon: Tutle publishing.

Destombe, C., Lejeune, L., Guillodo, Y., Roudaut, A., Jousse, S., Devauchelle, V., \& Saraux, A. (2006). Incidence and nature of karate injuries. Joint Bone Spine, 73, 182-188.

Ernst, B. (1992). Der Zauberspiegel des M. C. Escher. München: DTV.

Estevan, I., Álvarez, O., Falcó, C., \& Castillo, I. (2014). Self-efficacy and performance of the roundhouse kick in taekwondo. Revista de Artes Marciales Asiáticas, 9, 97-105.

Filaire, E., Sagnol, M., Ferrand, C., Maso, F., \& Lac, G. (2001). Psychophysiological stress in judo athletes during competitions. The Journal of Sports Medicine and Physical Fitness, 41(2), 263268.

Goodger, B.C., \& Goodger, J.M. (1977). Judo in the Light of Theory and Sociological Research. International Review for the Sociology of Sport, 12(2), 5-34

Haug, J.T., \& Haug, C. (2015). Von der Klassifikation der Vierecke zum System der Vierecke. The Teaching of Mathematics, 18, 1-15.

Hennig, W. (1994). Taschenbuch der speziellen Zoologie, Teil 1-Wirbellose 1 (ausgenommen Gliedertiere). Jena: Gustav Fischer.

Hergsell, G. (1887). Talhoffers Fechtbuch aus dem Jahre 1467, Gerichtliche und andere Zweikämpfe darstellend, Prag. Nachdruck VS-books 1999.

Hoff, F.F. (2008). IAI-DO: Blitzschnell die Waffe ziehen und treffen. Berlin: Weinmann.

Jamesa, A., \& Jonesa, R. (1982). The social world of karate-do. Leisure Studies, 1, 337-354.

Kernspecht, K.R. (2000). Vom Zweikampf: Strategie, Taktik, Physiologie, Psychologie, Philosophie und Geschichte der waffenlosen Selbstverteidigung. Burg auf Fehmarn: Wu Shu-Verlag.

Khan, K. (1999). Training with the Grandmaster. In M.V. Wiley (Ed.) The secrets of Cabales Serrada Escrima (pp. 54-57). North Clarendon: Tutle publishing.

Kurochkin, A., \& Khorasani, M.M. (2015). Indian and Persian swordsmanship: A Comparative Analysis. Revista de Artes Marciales Asiáticas, 10, 42-67.

Lantz. J. (2002). Family Development and the Martial Arts: A Phenomenological Study. Contemporary Family Therapy, 24, 565-580.

Leung, T. (1998). Wing Tsun Kuen. Burg auf Fehmarn: Wushu Verlag.

Luitger? (ca. 1300). Manuscript I.33 Royal Library Museum, British Museum no. 14Eiii, no. 20, D.vi "Tower Fechtbuch", "Würzburger Fechtbuch".

Mair, P.H. (1542). C 93/94. Dresden, Sächsische Landesbibliothek - Staats- und Universitätsbibliothek.

Nakayama, M. (1991). Nakayamas Karate perfekt 6. Kata 2: Bassai-Dai, Kanku-Dai. Niederhausen: Falken.

Pieter, J.W. (2003). Injury rates in adult elite judoka. Biology of Sport, 20, 25-32.

Pucsok, J.M., Nelson, K., \& Ng, E.D. (2001). A kinetic and kinematic analysis of the Harai-goshi judo technique. Acta Physiologica Hungarica, 88, 271-280.

Reif, W.-E. (2002). Evolution of organ systems: phylogeny, function and reciprocal illumination. Senckenbergiana lethaea, 82, 357-366.

Scheible, J. (1949). Jakob Sutor's künstliches Fechtbuch zum Nutzen der Soldaten, Studenten und Turner. Stuttgart: Scheible.

Sforza, C., Turci, M., Grassi, G., Fragnito, N., Pizzini, G., \& Ferrario, V.F. (2000). The repeatability of choku-tsuki and oi-tsuki in traditional shotokan karate: a morphological three-dimensional analysis. Perceptual and Motor Skills, 90, 947-960. 
Sforza, C., Turci, M., Grassi, G., Shirai, Y.F., Pizzini, G., \& Ferrario, V.F. (2002). Repeatability of maegeri-keage in traditional karate: a three-dimensional analysis with black-belt karateka. Perceptual and Motor Skills, 95, 433-444.

Siebert, G. (1995). Arnis, Escrima, Kali; Die Kunst der wirbelnden Stöcke; Lehrbuch für den Stockkampf. Berlin: Weinmann.

Sprague, M. (2003). The Science of Takedowns, Throws \& Grappling for Self-defense. Rockville: Turtle Press.

Tan, K.S.Y. (2004). Constructing a Martial Tradition: Rethinking a Popular History of Karate-Dou. Journal of Sport and Social Issues, 28, 169-192.

von Meyer, J. (1570). Gründtliche Beschreibung/der freyen Ritterlichen vnnd Adelichen kunst des Fechtens. Sig. Res 4 Gymn 26vt, Bayerische Staatsbibliothek München.

Wiley, M.V. (1999). The secrets of Cabales Serrada Escrima. North Clarendon: Tutle publishing.

Zetaruka, M.N., Violanb, M.A., Zurakowskic, D., \& Michelia, L.J. (2000). Karate injuries in children and adolescents. Accident Analysis \& Prevention, 32, 421-425.

\section{Author's biographical data}

Dr. Joachim T. Haug (Germany) is a zoologist working at the Ludwig-Maximilians-University Munich. He has been doing research on various biological fields, including functional morphology and systematics, leading to over 80 scientific publications so far. He has been teaching self-defense and martial arts for over 20 years. Interests reach from classical Asian or Asian-inspired martial arts (e.g. 1st Dan Bo-Jitsu, 2nd Dan Ju-Jutsu) over more modern approaches to European medieval fighting. He has been working on a systematic view beyond style boundaries for the last 15 years, with an emphasis on grappling-related techniques in the wide sense. E-mail: joachim.haug@palaeo-evo-devo.info.

Dr. Carolin Haug (Germany) is a researcher at the Functional Zoology work group of the LudwigMaximilians-University Munich. She has published over 60 scientific studies including systematic approaches and biomechanics. She has been training open martial arts for more than 15 years, including classical and modern Asian styles, but also historical European ones. Her main interest lies in a systematical understanding of armed combat with blade weapons. E-mail: carolin.haug@palaeo-evo-devo.info.

For more information, check the authors' homepage: www.palaeo-evo-devo.info 